\title{
How Consequential Is Social Epidemiology? A Review of Recent Evidence
}

\author{
Arijit Nandi • Sam Harper
}

Published online: 28 December 2014

(C) Springer International Publishing AG 2014

\begin{abstract}
A number of authors have suggested that epidemiology generally, and social epidemiology in particular, should be producing more consequential research to inform specific interventions for improving population health. However, the extent to which current research in social epidemiology prioritizes consequentialist questions is unknown. To provide some quantitative evidence on this question, we collected all abstracts accepted for either an oral or poster presentation at the annual meetings of the Society for Epidemiologic Research between 2009 and 2013. We identified all abstracts relating to the study of social determinants of health and classified each abstract as consequentialist if it evaluated the effect of a specific intervention. Among 619 abstracts examining social determinants of health, we classified 41 studies $(6.6 \%$ of total) as consequentialist, with minimal year-to-year variation. Little of social epidemiology appears to be focused on consequential research. Changes in pedagogy and greater involvement with the policy community may help.
\end{abstract}

Keywords Social epidemiology · Consequentialism · Neighborhood effects · Intervention studies · Causal inference $\cdot$ Public policy

Arijit Nandi and Sam Harper contributed equally to this work.

This article is part of the Topical Collection on Social Epidemiology

A. Nandi

Institute for Health and Social Policy, McGill University, Montreal,

QC, Canada

e-mail: arijit.nandi@mcgill.ca

A. Nandi $\cdot$ S. Harper $(\bowtie)$

Department of Epidemiology, Biostatistics \& Occupational Health,

McGill University, Montreal, QC, Canada

e-mail: sam.harper@mcgill.ca

A. Nandi $\cdot$ S. Harper

Centre on Population Dynamics, McGill University, Montreal, QC,

Canada

\section{Introduction}

For more than three decades, there has been an ongoing discourse about the fundamental role of epidemiologic science and the extent to which our research activities should directly inform efforts to prevent disease and improve population health [1]. While acknowledging the importance of describing the distributions of disease in populations and clarifying disease etiologies and mechanisms, a common thread in this discussion is that academic epidemiology spends most of its time on disease etiology and "far less of its time and imagination asking how we might improve population health" [2•]. Prominent epidemiologists, including William Foege [1], Willard Cates [3], and, most recently, Sandro Galea, have called for a more "consequentialist" epidemiology that prioritizes the "assessment of the potential contribution to population health of particular interventions implemented" [2•]. In the domain of social epidemiology, Patricia O'Campo recently questioned whether we are producing actionable evidence to address the social determinants of health and health inequality [4].

Consequentialism and Social Epidemiology

Social epidemiology, which is chiefly concerned with examining the role that social factors play in generating and sustaining health [5], has clear relevance to the discussion of consequentialism in epidemiologic research. Because the vision of consequential epidemiology described above is squarely focused on taking action to improve health, and such actions not only involve social planning but also have broad social consequences, social epidemiologists should be wellpositioned to inform this kind of work. Social epidemiology often comes in two varieties - descriptive and etiologic. Whereas the former tracks the social patterning of health outcomes, the latter focuses on understanding the causal effects of social exposures such as education, for example, on 
health outcomes. Generating evidence on the causal effects of modifiable social exposures naturally leads to questions about how to intervene to alter exposure distributions.

However, even if its efforts to uncover causal effects are successful, it is not clear that choosing a course of action for intervention based on rigorous evidence is well informed by current practice in social epidemiology. Take the example of the multitude of studies linking maternal education and infant mortality within and between countries [6-10]. Prominent social epidemiologists suggest that "the knowledge and the means are at hand" [11] to ameliorate such inequalities, but what is to be done? What course of action should "consequentialist" epidemiologists advocate for in order to address this persistent inequality? Should we take a "social determinants of health" approach and intervene directly on maternal education? If so, how? By making secondary education free? Making it compulsory? Perhaps we should focus on improving school quality? Or, absent interventions on maternal education, should we try to influence the mechanisms linking it to infant mortality, such as access to maternal care, targeted immunization coverage among kids of less-educated mothers, increasing control over household resources among lesseducated mothers, or increasing access to family planning? It could be a combination of several interventions and, of course, it is important to know which are most cost-effective.

But it is unclear whether social epidemiology as currently practiced is focusing much attention on these questions of action for specific interventions. A number of recent reflections on the current state of social epidemiology bemoan the discipline's lack of engagement with interventions to change health and reduce health inequalities [12•, 13-15]. For example, O'Campo et al. [15] recently argued that social epidemiologists should be pursuing evaluations of macro-level policies and programs in order to provide evidence on solutions to the complex problems that inhere in the production and maintenance of health inequalities. Moreover, though there is enormous heterogeneity across outcomes and environments, many social epidemiologists have argued that social inequalities in health are increasing, and that our efforts to reduce them, even as the specific target of policies, have not been successful [16]. Others argue that social epidemiology has failed to properly engage with policymakers, who suggest that the discipline is chiefly focused on finding associations rather than providing evidence on questions that are crucial for designing policy interventions [17].

There thus seems to be some consensus that social epidemiology "should" be producing evidence that would fall under the rubric of "consequentialist." Given the ongoing demands that social epidemiology produce research that is relevant for policy, and mostly qualitative arguments that the field has not made good on this agenda, we undertook a structured review of recent evidence presented at a highprofile conference to assess the extent to which social epidemiology is currently producing evidence that would contribute to a more "consequentialist" epidemiology.

\section{Methods}

\section{Search Strategy}

We reviewed abstracts accepted to annual meetings of the Society for Epidemiologic Research (SER) between 2009 and 2013 and evaluated trends in consequentialist research in the study of social determinants of health. The SER, founded in 1968, is one of the preeminent meetings of epidemiologic researchers in North America, and a review of accepted SER abstracts has been used previously to comment on the general direction of the field [18]. SER receives abstract submissions from members and non-members to be considered for presentation at the annual meeting. Submitted abstracts are reviewed by members of the Society, based on their areas of expertise. Each abstract is reviewed by a minimum of three individuals and is scored on a scale of 1 to 10 . Reviewer scores are averaged to determine the overall abstract score. Higher-ranking abstracts are then made available to organizers to arrange the Contributed Concurrent and Poster Sessions held at the annual meeting. Accepted abstracts are published in a special supplement to the American Journal of Epidemiology. We collected all abstracts accepted for either an oral or poster presentation at SER between 2009 and 2013.

We identified all abstracts relating to the study of social determinants of health. Posters sessions are organized by theme. For example, in 2013, the themes were aging, behavioral, cancer, cardiovascular, diabetes, environmental, genetics, global health, health services, history, HIV, infection, injury, latebreakers, men's health, methods, neuro epi, nutrition, obesity, occupational, pediatrics, perinatal/reproductive, psychiatric, renal, respiratory, screening, social, substance use, and women's health. Concurrent Contributed Sessions in 2013 are collections of abstracts that are selected by researchers appointed by SER for oral presentations concerning a specific theme. From poster and spotlight sessions, we automatically selected all abstracts presented in thematic areas related to the study of social determinants and then reviewed all other topic areas for additional studies. We adopted a sensitive definition of social determinants, erring on the side of including studies for review.

We next reviewed the text of all abstracts related to the study of social determinants of health, among all abstracts accepted for presentation. From each abstract, we collected the following information: author affiliation; title; whether the abstract related to the study of social determinants of health; the setting, including the country or countries where the work was conducted; the main exposure(s); and the outcome(s). We 
then independently reviewed and judged whether each abstract was "consequentialist" or not. We defined a study as consequentialist if it evaluated (or simulated) the effect of a specific intervention. After we completed our assessments, we examined the agreement, measured by the Kappa statistic. We reconciled any disagreements in our ratings and identified a final set of abstracts deemed consequentialist.

\section{Results}

Between 2009 and 2013, a total of 619 abstracts examining social determinants of health were accepted for a poster or spotlight presentation. The overall agreement between our evaluations was excellent (Kappa $=0.88)$. After reconciling disagreements in our assessments, 41 studies ( $6.6 \%$ of total) were deemed consequentialist. The proportion of abstracts that we classified as consequentialist was $5.8 \%$ in 2009 , $4.3 \%$ in 2010, $5.2 \%$ in 2011, $6.3 \%$ in 2012, and $12.7 \%$ in 2013 (Fig. 1). We identified two general streams of consequentialist research: (1) observational studies where the investigators had no control over the assignment of the treatment (e.g., a policy) and (2) experimental studies where they did. That is, we only considered as "experimental" studies for which the manipulation of the exposure or intervention was under the control of the researcher (including simulation studies). A summary of the abstracts identified as consequentialist is provided in Table 1 .

\section{Observational Studies}

Among the 41 papers that evaluated the effect of a specific intervention, 25 (61 \%) were observational studies. In most cases, these studies evaluated the effects of changes in (1) social policies and programs (abstracts 1, 2, 5, 6, 8-10, 12, 13, $15,25)$ and $(2)$ public health and health services interventions (abstracts 11, 16, 20, 21, 24), including several policies targeting alcohol (abstracts 17, 22) and tobacco (abstracts 3 , $4,7,14,18,19,23)$ use.

\section{Experimental Studies}

A total of 16 of the 41 (39\%) consequentialist papers used an experimental design. Several studies evaluated the effects of randomized interventions (abstracts 34, 40, 41), including the Moving to Opportunity (MTO) experiment (abstracts 33, 35, $36,38,39)$. Other studies evaluated the non-random assignment of participants to various school, workplace, and community-based health interventions (abstracts 26, 28, 30 $32,37)$. Two studies used simulated data to evaluate the effect of specific interventions, including an educational policy that
Fig. 1 Consequentialism in social epidemiology, SER annual meetings, 2009-13

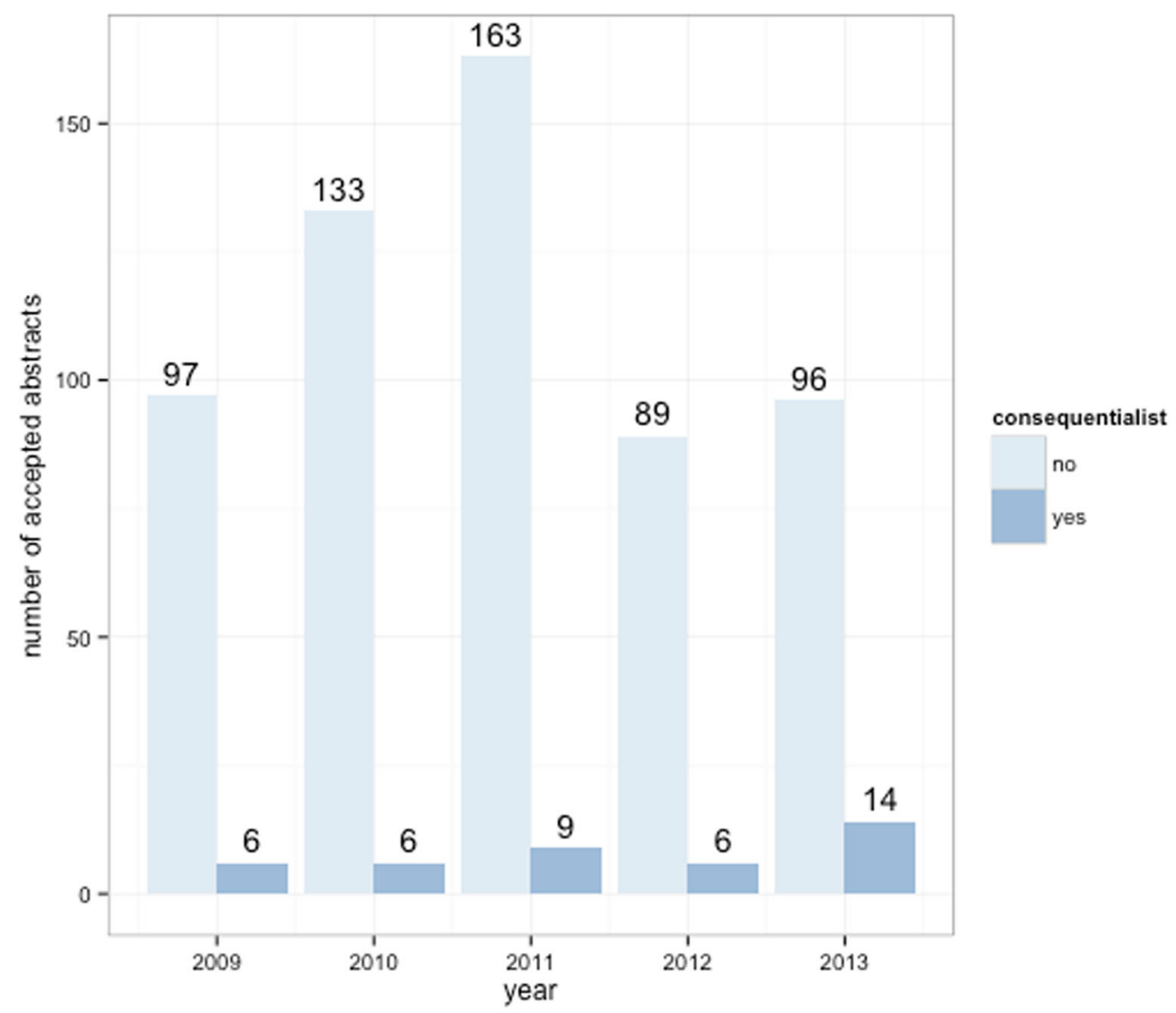


Table 1 Summary of consequentialist studies in social epidemiology among abstracts accepted to SER annual meetings, 2009-2013

\begin{tabular}{|c|c|c|c|c|c|}
\hline Abstract & Year & Title & Setting & Primary exposure & Main outcome(s) \\
\hline \multicolumn{6}{|c|}{ Observational studies } \\
\hline 1 & 2009 & $\begin{array}{l}\text { The Impact Of A Baby Bonus Payment } \\
\text { On Birth Rates In Australia }\end{array}$ & $\begin{array}{l}\text { Australia: Australian } \\
\text { Bureau of Statistics } \\
\text { 1997-2006 }\end{array}$ & Baby bonus (policy) & Birth rate trends \\
\hline 2 & 2009 & $\begin{array}{l}\text { Income Shocks And Very Low Weight } \\
\text { Births Among Black Mothers In } \\
\text { California }\end{array}$ & California & $\begin{array}{l}\text { Earned Income Tax Credit } \\
\quad \text { (policy/shock) }\end{array}$ & Very low birth weight \\
\hline 3 & 2009 & $\begin{array}{l}\text { A Multilevel-Based Study Of School } \\
\text { Policy For Tobacco Control In Relation } \\
\text { To Cigarette Smoking Among Children }\end{array}$ & $\begin{array}{l}\text { Taiwan: school-based } \\
\text { sample }\end{array}$ & School tobacco policy & Student smoking \\
\hline 4 & 2010 & $\begin{array}{l}\text { The Impact Of Tobacco Control Policies } \\
\text { On Disparities In Children's } \\
\text { Secondhand Smoke Exposure }\end{array}$ & $\begin{array}{l}\text { United States: National } \\
\text { Survey of Children's } \\
\text { Health (2003-2007) }\end{array}$ & $\begin{array}{l}\text { Smoke-free legislation \& } \\
\text { cigarette excise taxes }\end{array}$ & Household tobacco use \\
\hline 5 & 2010 & $\begin{array}{l}\text { Can Neighborhood Policy Interventions } \\
\text { Improve Health? Quasi-Experimental } \\
\text { Evidence From Medellín, Colombia }\end{array}$ & Medellın, Colombia & Construction of a gondola & $\begin{array}{l}\text { Alcohol use, perceived } \\
\text { violence, homicide, } \\
\text { behavioral outcomes, } \\
\text { illicit drug use }\end{array}$ \\
\hline 6 & 2010 & $\begin{array}{l}\text { School Desegregation And Associated } \\
\text { Decreases in Female Adolescent Births }\end{array}$ & $\begin{array}{l}\text { United States Census } \\
\text { Data }(1970 / 1980)\end{array}$ & School desegregation policy & $\begin{array}{l}\text { Prevalence of births to } \\
\text { adolescents }\end{array}$ \\
\hline 7 & 2010 & $\begin{array}{l}\text { A Multilevel-Based Study Of Clustering } \\
\text { In Cigarette Smoking Behavior In } \\
\text { Relation To Individual- And } \\
\text { School-Level Characteristics Among }\end{array}$ & Taiwan: 52 schools & $\begin{array}{l}\text { School-level (smoking policies, } \\
\text { etc.) \& individual-level } \\
\text { (alcohol use, family smoking, } \\
\text { etc.) characteristics }\end{array}$ & Smoking \\
\hline
\end{tabular}

82010 Causal Inferences From Longitudinal Marginal Structural Models: Effect Of 10 Years Participation In A Conditional Cash Transfer Program On Children's Social-Behavioral Development

92011 Public Housing Policy Change And Residential Mobility Predict Low Birthweight-Preterm Birth

102011 The Impact Of Poverty Reduction Policy On Child And Adolescent Overweight: A Quasi- Experimental Analysis Of The Earned Income Tax Credit

112011 The Supplemental Nutrition Assistance Program: Differences In Dietary Intake Between Participants And Low-Income Nonparticipants

122011 Decrease Trend In Common-Cause Adolescent Mortality Rates Following School Desegregation Legislation, Us 1968-1988

132012 Effects Of State-Level Policies On Risk Behavior In Men Who Have Sex With Men

142012 The Effect Of The Smoke-Free Ordinance On Acute Myocardial Infarction In South Carolina

152012 Difference In Difference Estimates Of The Effect Of An Income Benefit Policy On Food Insecurity In Families With Young Children

162012 Use Of Propensity Score Matching To Assess The Effect Of A State Policy On Treatment Outcomes In U.S. HIV-Infected Persons

172013 Effects Of Minimum Legal Drinking Age On Alcohol And Marijuana Use: Evidence From Toxicological Testing Data For Fatally Injured Drivers Aged 16 To 25 Years
Mexico: Oportunidades (1997-2007)

Atlanta, GA: cohort of women who lived in public housing from 1994 to 2007

United States: Children and Young Adults of the National Longitudinal Survey of Youth 1979 (1986-2006)

United States: NHANES subset (1999-2008)

United States, 123 counties: Vital Statistics mortality records (1968-1988)

United States: men recruited from sex-seeking websites

Greenville, Charleston, \& Spartanburg, SC: health claims data

Canada: cross-sectional Canadian health surveys (2000-2009)

United States: NA-ACCORD Use of waiting lists for AIDS (2001-2007)

13 US States Drug Assistance Program enrollment in a participant's state of residence

Minimum legal drinking age

family income

\section{Supplemental Nutrition Assistance Program (SNAP) participation}

Changes in school desegregation policy

State-level gay rights policies

Smoke-free ordinances (city level)

Universal Child Benefit (policy)
Child's social-behavioral development

Low birth weight-preterm birth

Child overweight
Dietary intake patterns/quality

Childhood/adolescent mortality

Sexual \& alcohol risk behaviors

Acute myocardial infarction hospitalizations

Self-reported food insecurity

Time to ART initiation, HIV viral load suppression

Alcohol and marijuana use 
Table 1 (continued)

\begin{tabular}{|c|c|c|}
\hline Abstract & Year & Title \\
\hline 18 & 2013 & $\begin{array}{l}\text { The Impact Of Tobacco Control Policies } \\
\text { On Disparities In Maternal Smoking } \\
\text { During Pregnancy. }\end{array}$ \\
\hline 19 & 2013 & $\begin{array}{l}\text { Income As An Effect Modifier In The } \\
\text { Relationship Between Smoke-Free } \\
\text { Car Rules And Childhood Asthma }\end{array}$ \\
\hline 20 & 2013 & $\begin{array}{l}\text { Has Massachusetts Health Care Reform } \\
\text { Worked For The Working Poor? }\end{array}$ \\
\hline 21 & 2013 & $\begin{array}{l}\text { What Does The Massachusetts Experience } \\
\text { Tell Us About The Potential Impact Of } \\
\text { The Affordable Care Act On The Use } \\
\text { Of Clinical Preventive Services? }\end{array}$ \\
\hline 22 & 2013 & $\begin{array}{l}\text { Evaluating The Effects Of The } \\
\text { Introduction Of Off- Sale Alcohol } \\
\text { Outlets On Violent Crime }\end{array}$ \\
\hline 23 & 2013 & $\begin{array}{l}\text { Public Smoking Legislation And } \\
\text { Hospitalizations For Ischemic Heart } \\
\text { Disease In Atlantic Canada, 1996-2010: } \\
\text { Mixed-Effects Modeling Of Multilevel } \\
\text { Population Health Interventions }\end{array}$ \\
\hline 24 & 2013 & $\begin{array}{l}\text { The Effect Of A Delivery Fee Exemption } \\
\text { Policy On Socioeconomic Inequalities } \\
\text { In Health Facility Deliveries: A } \\
\text { Difference-In-Differences Analysis } \\
\text { From Five West African Countries }\end{array}$ \\
\hline 25 & 2013 & $\begin{array}{l}\text { Social Participation And Drug Use In } \\
\text { A Cohort Of Brazilian Sex Workers }\end{array}$ \\
\hline
\end{tabular}

Experimental studies

262009 Evaluation Of A Community-Based Intervention To Increase Breast Cancer Screening And Early Detection Among Low-Income, African American Women

272009 Modeling The Implications Of Non-Health Educational Policies For Cardiovascular Disease Incidence And Mortality

282009 Long-Term Impact Of A School-Based Intervention On Knowledge, Dietary Intakes And Physical Activity Among Primary School Children

292010 How Long Does It Take To Reduce Inequalities In Lung Cancer Incidence Through Smoking Policies?

302011 Evaluation Of A Community-Based Intervention To Increase Breast Cancer Screening And Early Detection Among Low-Income, African American Women

312011 Performance Of Mobile Units Of The Quebec Breast Cancer Screening Program, 2002-2009

$32 \quad 2011$ Financial Incentive For Promoting Good-Health Behaviors In The Workplace

332011 Mental Health Effects Of A Housing Mobility Program By Vulnerable Subgroups: Who Benefits From Moves To Low-Poverty Neighborhoods?

Setting

29 US States

United States; BRFSS

Massachusetts; Boston Area Massachusetts health care Community Health Survey

Massachusetts; BRFSS

Lubbock, Texas

Canada

Main outcome(s)

West Africa

Corumbá, Brazil

Savannah \& Macon, Georgia

Not indicated

Not indicated (possibly Trinidad \& Tobago)

Not applicable

Savannah \& Macon, GA: National Breast and Cervical Cancer Early Detection Program

Quebec: Breast Cancer Screening Program

A large agribusiness (location not indicated)

United States: Moving to Opportunity study

Arak, Iran reform

Massachusetts health care reform

Tobacco control policies

Smoke-free car rules

Policy that ended prohibition of off-sale alcohol outlets

Public smoking legislation

Fee exemption policy

Educational intervention

Disparities in maternal smoking during pregnancy

Childhood asthma

Health insurance coverage

Clinical preventive service use

Violent crime

Hospitalizations for ischemic heart disease

Socioeconomic inequalities in health facility deliveries

Drug use participation by drug users in external social groups

Breast cancer survivor testimonials on radio stations with wide African American listenership

Sustained school funding

Region-specific calls to the Cancer Information Service's hotline

Cardiovascular disease

School-based nutrition intervention program

Projected increases in cigarette prices \& health advertisements

Multimedia breast cancer awareness campaign

Mammogram receipt

Mobile screening units

Financial incentive worksite wellness program

MTO voucher receipt (by gender \& baseline health vulnerability)
Knowledge, dietary intakes and physical activity among children attending primary school

Lung cancer \& gap by SES

Screening participation \& performance

General health \& health behaviors, including BMI, lipids, fat intake, mental well-being

Psychological distress

Knowledge re: healthy lifestyles 
Table 1 (continued)

\begin{tabular}{|c|c|c|c|c|c|}
\hline Abstract & Year & Title & Setting & Primary exposure & Main outcome(s) \\
\hline 35 & 2012 & $\begin{array}{l}\text { Did Adolescents In Higher SES Families } \\
\text { Differentially Benefit From A } \\
\text { Housing Mobility Intervention? }\end{array}$ & $\begin{array}{l}\text { United States: Moving to } \\
\text { Opportunity study }\end{array}$ & $\begin{array}{l}\text { Moving voucher receipt } \\
\text { family SES at baseline }\end{array}$ & $\begin{array}{l}\text { Psychological distress \& } \\
\text { behavioral problems }\end{array}$ \\
\hline 36 & 2012 & $\begin{array}{l}\text { Effects Of Housing Mobility And Lower } \\
\text { Poverty Neighborhoods On Adolescent } \\
\text { Asthma: The Moving To Opportunity } \\
\text { Experiment }\end{array}$ & $\begin{array}{l}\text { United States: Moving to } \\
\text { Opportunity study }\end{array}$ & Moving voucher receipt & Youth asthma \\
\hline 37 & 2013 & $\begin{array}{l}\text { The Microclinic Health Program: A } \\
\text { Sowrk- Based Intervention For } \\
\text { Weight Loss And } \\
\text { Diabetes Risk Management }\end{array}$ & Amman, Jordan & $\begin{array}{l}4 \text { month diabetes education } \\
\text { program }\end{array}$ & $\begin{array}{l}\text { Clinical markers (weight, } \\
\text { Body Mass Index [BMI], } \\
\text { and Hemoglobin } \\
\text { A1c }[\text { HbAlc] })\end{array}$ \\
\hline 38 & 2013 & $\begin{array}{l}\text { The Moving To Opportunity Experiment } \\
\text { And Adolescent Psychological Distress: } \\
\text { Were Effects Mediated By Neighborhood } \\
\text { Characteristics? }\end{array}$ & $\begin{array}{l}\text { United States; Moving to } \\
\text { Opportunity study }\end{array}$ & $\begin{array}{l}\text { Randomized section } \\
8 \text { vouchers } \\
\text { or public housing (control) }\end{array}$ & $\begin{array}{l}\text { Adolescent psychological } \\
\text { distress }\end{array}$ \\
\hline 39 & 2013 & $\begin{array}{l}\text { Effects Of A Housing Mobility Experiment } \\
\text { On Neighborhood Quality. }\end{array}$ & $\begin{array}{l}\text { United States; Moving to } \\
\text { Opportunity study }\end{array}$ & $\begin{array}{l}\text { Randomized section } 8 \text { vouchers } \\
\text { or public housing (control) }\end{array}$ & $\begin{array}{l}\text { Neighborhood economic } \\
\text { conditions, including } \\
\text { neighborhood disorder, } \\
\text { collective efficacy, and } \\
\text { violent crime }\end{array}$ \\
\hline 40 & 2013 & $\begin{array}{l}\text { A Social Network Intervention For } \\
\text { Reducing Influenza- Like Illness } \\
\text { Transmission: The Ex-Flu Cluster } \\
\text { Randomized Trial }\end{array}$ & $\begin{array}{l}\text { United States: university } \\
\text { students living in } \\
\text { residence halls }\end{array}$ & $\begin{array}{l}\text { Randomized to 3-day or 6-day } \\
\text { sequestration vs. } \\
\text { none (control) }\end{array}$ & Influenza-like illness \\
\hline 41 & 2013 & $\begin{array}{l}\text { Gender Differences In Effect Of Reduction } \\
\text { in Alcohol Use On HIV Risk Behaviors } \\
\text { In Tomsk, Russian Federation }\end{array}$ & Tomsk, Russian Federation & Randomized alcohol treatment & HIV risk behavior \\
\hline
\end{tabular}

provided sustained school funding (abstract 27) and a smoking policy that increased cigarette prices and health advertisements (abstract 29).

\section{Discussion}

We evaluated the extent to which recent epidemiologic research on the study of social determinants of health can be considered consequentialist. We identified few studies that evaluated specific social interventions for improving health or reducing health inequalities (including our own work). This is not a novel observation. Prior work has hinted at imbalances between social epidemiology's research goals and its research outputs. Bonneux noted in 2007 that, while our field faces "a feast of descriptive studies of socio-economic causes of ill health, we still face a famine of evaluative intervention studies" [19]. Our informal review of the current state of the science suggests that the scarcity of evaluative intervention studies has persisted since this observation.

Whether the predominance of descriptive over consequentialist work in social epidemiology impedes our ability to act on the social determinants of health is unclear. But if we assume there is at least some utility for policy-related evidence demonstrating how social interventions can be used to improve health and reduce social inequalities in health, the current shortage of consequentialist studies certainly does not help. Reiterating a decade-old argument for incorporating "experimental and quasi-experimental designs evaluating the potential health impacts of social and economic policies" [20], we suggest (again) that a greater emphasis on evaluations could make social epidemiology more policy relevant. Before underlining some of the barriers that may contribute to the underutilization of evaluation studies and recommending some practical solutions, we illustrate the urgency for a more consequentialist social epidemiology using a case study on neighborhood effects research.

\section{Neighborhood Effects on Health}

There has been an explosion of interest in neighborhood health effects over the past two decades, due in large part to the proliferation of methods for multilevel statistical analysis $[21,22]$. This was evident in our review-nearly one-quarter of social epidemiology abstracts presented at SER over the past 5 years could be characterized as neighborhood effects studies. Like the study of social determinants more generally, much of this work has been observational, including some descriptive research (e.g., estimating social or racial inequalities in health across neighborhood boundaries) as well as "associational" studies that have frequently examined whether characteristics of neighborhoods - including their social conditions, physical environments, and racial composition- 
influence health [21-24]. Despite occupying a substantial amount of social epidemiology's research activity, we categorized few $(n=7)$ neighborhood effects studies as consequentialist; important methodological and substantive challenges might explain this unevenness.

An established methodological critique of research into neighborhood effects is that the influence of neighborhood conditions on health can seldom be characterized as causal $[25,26]$. Substantial attention has been given to the nonexchangeability of individuals living in different types of neighborhoods owing to neighborhood selection, i.e., the non-random migration of individuals into and out of particular neighborhoods based on characteristics that may be related to their health. By limiting the exchangeability of neighborhood contrasts, neighborhood selection presents a "methodological wall" that usually limits causal inference in observational studies of neighborhood effects and, as others have noted $[25,27,28]$, challenges the policy relevance of research findings. Moreover, varying definitions of what constitutes a neighborhood - often (though not always) a consequence of reliance on administrative data - can lead to heterogeneity for the same exposure-outcome association [29, 30].

Our review, which attempted to apply a consequentialist lens to the literature, identifies an additional challenge to the policy relevance of most existing neighborhood effects research. Consider the following thought experiment: were we to live in a counterfactual world where neighborhood selection was not a pervasive methodological challenge, and could conclude that neighborhood conditions have a causal impact on health, would we be able to recommend evidence-based interventions for neighborhood interventions to improve health? In most cases, these interventions would be difficult to articulate, since neighborhood effects studies have not sought to identify specific interventions for manipulating features of the neighborhood environment that influence health [31]. In many cases, neighborhood exposures are defined based on summary indexes (such as deprivation scores) derived from data reduction techniques [32], which are useful in some respects but tell us little about which specific exposures matter for health. But even isolating simple, modifiable neighborhood factors tells us little about whether or how to change them. Even if we knew, for example, that neighborhood poverty, one of the most frequently assessed neighborhoodlevel exposures, exerted a causal effect on health, it would be difficult given the current state of the science to identify a realworld intervention to influence distributions of poverty across neighborhoods.

The distinction between the methodological challenge posed by neighborhood selection and the challenge of identifying interventions for improving health associated with adverse neighborhood conditions is illustrated by the Moving to Opportunity (MTO) study. MTO was a housing relocation experiment conducted in five US cities that provided families living in public housing in high poverty neighborhoods with the opportunity to move to lower poverty neighborhoods [33]. The opportunity to move was randomly assigned through the use of housing vouchers, thereby solving the selection issue. However, MTO does not provide a clear answer to the consequentialist question of how neighborhood environments could be changed to improve population health because it examined the effect of moving families to new neighborhoods rather than the effect of a policy-relevant neighborhood-level intervention on current neighborhoods [21]. Five of the seven papers (abstracts 33, 35, 36, 38, 39) that analyzed the effect of a specific neighborhood intervention were evaluations of the MTO housing mobility experiment.

The challenges to a more consequentialist neighborhood effects epidemiology are not insurmountable. However, given the increasing frequency of studies evaluating neighborhood effects [34], a course correction is sorely needed. Within the domain of observational research, quasi-experimental evaluations can be used to estimate the effects of specific policyrelevant changes in neighborhood environments, while simultaneously addressing the issue of neighborhood selection. Identifying quasi-experiments is, however, difficult and published examples in the neighborhood effects literature are sparse. One study identified by our review (abstract 5) evaluated the effect of an intervention in neighborhood physical infrastructure, specifically the construction of a public transit system in Medellín, Colombia that connected isolated lowincome neighborhoods to the city center, on levels of reported violence using a propensity score-matched difference-indifferences design [35•]. This study, by exploiting arguably exogenous variation in neighborhood conditions, avoided the potential self-selection of individuals into different neighborhoods. Moreover, by examining the effect of a "natural experiment," the study identified a specific intervention for influencing health (or in this case violence) by changing the neighborhood environment, although the generalizability of this intervention to other contexts might be limited. Another study used quasi-experimental [36] and experimental [37] methods to estimate the effects of a neighborhood greening initiative on health and safety in Philadelphia. Though experimental studies for estimating policy-relevant neighborhood effects are rare, they may pay large dividends in terms of strengthening the evidence base for neighborhood effects. According to Oakes, "for those wishing to stay focused on neighborhood effects, (experimental) research into specific policy-relevant changes of neighborhood environments would be most helpful" [38].

\section{Different Approaches to Consequentialism}

Although a small proportion of studies in our sample were classified as consequentialist, these studies adopted a variety of approaches, which suggests that consequential research in 
social epidemiology can be delivered through a diversity of research designs. We do not need to rehearse here the ample arguments for not adhering rigidly to hierarchies of evidence [39], but different design and analysis strategies are likely to have strengths and weaknesses for a given research question. Randomized interventions have clear advantages with respect to internal validity, but social interventions often lead to lots of non-compliance (as in the MTO example above), and even trials with good compliance may not be generalizable to other contexts. Recent work has formalized the assumptions and outlined methods for generalizing RCT evidence to other populations [40], and this could perhaps be applied more widely. For non-randomized designs, prioritizing highquality natural experiments seems another promising strategy. Natural experiments where treatment assignment is not under researcher control - but is truly random (e.g., lottery) or as good as random - maintain some of the advantages of RCTs, but may also be more generalizable since they occur in less selected populations. But natural experiments are often hard to come by, and require solid combinations of quantitative and qualitative knowledge about the intervention to be credible [41]. In other cases, there may exist no reasonable combination of available data and identification strategy to estimate the impact of a given intervention. A variety of simulation models have become popular for answering questions about the impact of interventions on population health [42-44], and can be extended to assess impact on health inequalities $[45,46]$. Clearly, they may have benefits with respect to adaptability and control of the researcher over the system parameters. However, convincing simulation models need validation [47] and depend heavily on the quality of the input parameters. Given the small fraction of articles in our sample that provided any evidence on the impact of interventions, this may make developing and applying simulation models for consequential social epidemiology challenging.

\section{Limitations}

There were several limitations to our approach. First, the definition of consequentialism is itself subjective. Our characterization of consequentialist research as research that evaluates or simulates a specific intervention follows from our interpretation of the prior literature $[1,2 \bullet, 3,4]$; however, reasonable social epidemiologists can disagree about the policy relevance of a given study (though we rarely did). This caveat considered a broader definition would be unlikely to qualitatively change our main conclusions regarding the extent of consequentialism in social epidemiology. Second, our review was based on abstracts accepted to the SER annual meeting, and this selection of work is an imperfect proxy for the current state of social epidemiology. SER draws submissions primarily from North America, and the USA in particular, and work from other regions is likely underrepresented.
Third, our review was based on accepted abstracts, not published peer-reviewed papers; however, this might be considered a strength and more accurately reflect current research priorities given pervasive publication bias. Fourth, the abstracts included in 2011 were submitted to the World Congress of Epidemiology, a joint meeting of professional organizations including SER; the abstracts selected from this year represent a broader catchment area.

\section{Recommendations}

As Galea and Link recently noted, there is much that we can learn from studying interventions [14]. However, "recalibrating" our field and shifting our propensity for descriptive or "etiologic" analyses toward evaluative research will require changing some deeply entrenched behaviors. For one, it will require us to modify our approach to training and integrate interdisciplinary methods for analyzing interventions. Few training programs targeted to social epidemiologists provide an adequate foundation for applying experimental or quasi-experimental methods for evaluating the effects of interventions. Certainly, some of the methods that have been a core component of standard epidemiologic curricula, such as randomized controlled trials, are apposite to the evaluation of social interventions, although more emphasis on treatments defined at the "cluster" level, as well as the challenges this entails, is needed. However, by and large, quasi-experimental methods frequently applied in policy evaluation, including difference-in-differences and instrumental variable approaches, are not part of the social epidemiologist's armamentarium. They should be. We are starting to see a translation of these methods from the economics literature into epidemiologic parlance [48], which will hopefully stimulate their utilization, but exposing students to interdisciplinary methods for impact evaluation during their training programs can help advance a more consequentialist social epidemiology. A second challenge to producing consequentialist evidence is asking a policy-relevant research question. As we illustrated in our case study, estimating a causal effect is a necessary but not sufficient condition for producing consequentialist evidence because research estimating the causal effects of treatments that do not correspond to some practicable intervention is unlikely to be considered policy-relevant $[49,50]$. Involving "knowledge users," including non-governmental and governmental actors, in the research process and identifying relevant research gaps can help in designing and articulating policy-relevant research questions [17, 51]. Third, periodically and systematically reviewing the literature concerning the health effects of specific social interventions can be useful for synthesizing results, identifying research gaps, understanding heterogeneity, and reducing redundancies $[52 \bullet \bullet, 53]$. 


\section{Concluding Remarks}

Social epidemiology has made substantial progress since its inception. The investigation of how multilevel determinants of health and health inequalities, spanning from the molecular to the individual to the macro-level, has distinguished social epidemiology from other branches of epidemiology and formalized its role in the social sciences. However, for it to consolidate its position and maintain its relevance, social epidemiology will have to demonstrate that it cannot only elucidate how social factors influence population health but also prescribe evidence-based interventions for acting on them. Through this review and commentary, we have examined the extent of and challenges to a more consequentialist epidemiology. Overcoming these challenges will require another phase of "intense socialization and learning" [54] that include engaging with key stakeholders, articulating policyrelevant research questions, and applying interdisciplinary research designs and methods for answering them.

\section{Compliance with Ethics Guidelines}

Conflict of Interest A Nandi and S Harper declare that they have no conflict of interest.

Human and Animal Rights and Informed Consent All studies by the authors involving animal and/or human subjects were performed after approval by the appropriate institutional review boards. When required, written informed consent was obtained from all participants.

Source of Funding The authors acknowledge funding from the Canadian Institutes of Health Research Operating Grant, "Examining the impact of social policies on health equity" (ROH-115209). AN is supported by the Canada Research Chairs program. SH is supported by a Chercheur-boursier Junior 2 from the Fonds de recherche du QuébecSanté.

\section{References}

Papers of particular interest, published recently, have been highlighted as:

- Of importance

-• Of major importance

1. Marks JS. Epidemiology, public health, and public policy. Prev Chron Dis. 2009;6(4):A134.

2. Galea S. An argument for a consequentialist epidemiology. Am J Epidemiol. 2013;178(8):1185-91. Provides an overview of what consequentialist program of research would look like in epidemiology and how we might achieve it.

3. Cates W. Invited Commentary: Consequential (ist) epidemiology: let's seize the day. Am J Epidemiol. 2013;178(8):1192-4.

4. O'Campo P. Are we producing the right kind of actionable evidence for the social determinants of health? J Urban Health. 2012;89(6): 881-93.
5. Kaufman JS. Social epidemiology. In: Rothman KJ, Greenland S, Lash TL, editors. Modern epidemiology. 3rd ed. Philadelphia: Wolters Kluwer Health/Lippincott Williams \& Wilkins; 2008. p. 533-48.

6. WHO Commission on Social Determinants of Health. Closing the gap in a generation: health equity through action on the social determinants of health. Final report of the Commission on the Social Determinants of Health. Geneva: World Health Organization, Commission on Social Determinants of Health; 2008.

7. Gakidou E, Cowling K, Lozano R, Murray CJL. Increased educational attainment and its effect on child mortality in 175 countries between 1970 and 2009: a systematic analysis. Lancet. 2010;376(9745):959-74.

8. Cleland JG, Van Ginneken JK. Maternal education and child survival in developing countries: the search for pathways of influence. Soc Sci Med. 1988;27(12):1357-68.

9. Singh GK, Kogan MD. Persistent socioeconomic disparities in infant, neonatal, and postneonatal mortality rates in the United States, 1969-2001. Pediatrics. 2007;119(4):e928-39.

10. Ware H. Effects of maternal education, women's roles, and child care on child mortality. Pop Dev Rev. 1984;10:191-214.

11. Marmot M, Friel S, Bell R, Houweling TAJ, Taylor S. Closing the gap in a generation: health equity through action on the social determinants of health. Lancet. 2008;372(9650):1661-9.

12. Oakes JM. Invited commentary: paths and pathologies of social epidemiology. Am J Epidemiol. 2013;178(6):850-1. Describes several concrete steps that social epidemiology could take to make its research more successful.

13. Muntaner C. Invited commentary: on the future of social epidemiology — a case for scientific realism. Am J Epidemiol. 2013;178(6): 852-7.

14. Galea S, Link BG. Six paths for the future of social epidemiology. Am J Epidemiol. 2013;178(6):843-9.

15. O'Campo P. Are we producing the right kind of actionable evidence for the social determinants of health? J Urban Health. 2012;89(6): 881-93.

16. Mackenbach JP. Has the English strategy to reduce health inequalities failed? Soc Sci Med. 2010;71(7):1249-53. discussion 54-8.

17. Petticrew M, Whitehead M, Macintyre SJ, Graham H, Egan M. Evidence for public health policy on inequalities: 1: the reality according to policymakers. J Epidemiol Community Health. 2004;58(10):811-6.

18. Skrabanek P. The poverty of epidemiology. Perspect Biol Med. 1992;35(2):182-5.

19. Bonneux L. From evidence based bioethics to evidence based social policies. Eur J Epidemiol. 2007;22(8):483-5.

20. Berkman LF. Introduction: seeing the forest and the trees-from observation to experiments in social epidemiology. Epidemiol Rev. 2004;26:2-6.

21. Diez Roux AV. Neighborhoods and health: where are we and were do we go from here? Rev Epidemiol Sante Publique. 2007;55(1): 13-21.

22. Diez Roux AV. Investigating neighborhood and area effects on health. Am J Public Health. 2001;91(11):1783-9.

23. Diez Roux AV, Mair C. Neighborhoods and health. Ann N Y Acad Sci. 2010;1186:125-45.

24. Nandi A, Kawachi I. Neighborhood effects on mortality. In: Rogers RG, Crimmins EM, editors. International handbook of adult mortality. Dordrecht: Springer; 2011. p. 413-39.

25. Oakes JM. The (mis)estimation of neighborhood effects: causal inference for a practicable social epidemiology. Soc Sci Med. 2004;58(10):1929-52.

26. Oakes JM. Commentary: advancing neighbourhood-effects research - selection, inferential support, and structural confounding. Int J Epidemiol. 2006;35(3):643-7. 
27. Diez Roux AV. Estimating neighborhood health effects: the challenges of causal inference in a complex world. Soc Sci Med. 2004;58(10):1953-60.

28. Harding DJ. Counterfactual models of neighborhood effects: the effect of neighborhood poverty on dropping out and teenage pregnancy. Am J Sociol. 2003;109(3):676-719.

29. Openshaw S. The modifiable areal unit problem. Norwich: Geo Books; 1983.

30. Parenteau MP, Sawada MC. The modifiable areal unit problem (MAUP) in the relationship between exposure to $\mathrm{NO} 2$ and respiratory health. Int J Health Geogr. 2011;10:58.

31. Morenoff J, Diez Roux A, Hansen B, Osypuk TL. Residential environments and obesity: what can we learn about policy interventions from observational studies? Making Americans healthier: social and economic policy as health policy. New York: Russell Sage; 2008. p. 309-43.

32. Messer LC, Kaufman JS. Measuring health inequalities. In: Oakes JM, Kaufman JS, editors. Using census data to approximate neighborhood effects. San Francisco: Jossey-Bass; 2006. p. 209-36.

33. Leventhal T, Brooks-Gunn J. Moving to opportunity: an experimental study of neighborhood effects on mental health. Am J Public Health. 2003;93(9):1576-82.

34. Oakes JM, Andrade KE, Biyoow I, Cowan LT. Twenty Years of Neighborhood Effect Research: An Assessment. Curr Epidemiol Rep. forthcoming.

35. Cerdá M, Morenoff JD, Hansen BB, et al. Reducing violence by transforming neighborhoods: a natural experiment in Medellín, Colombia. Am J Epidemiol. 2012;175(10):1045-53. An excellent example of a well-designed neighborhood effects study focused on providing evidence on the health impacts of a specific intervention.

36. Branas CC, Cheney RA, MacDonald JM, Tam VW, Jackson TD, Ten Have TR. A difference-in-differences analysis of health, safety, and greening vacant urban space. Am J Epidemiol. 2011;174: 1296-306.

37. Garvin EC, Cannuscio CC, Branas CC. Greening vacant lots to reduce violent crime: a randomised controlled trial. Inj Prev. 2013;19(3):198-203.

38. Oakes JM. Invited commentary: repeated measures, selection bias, and effect identification in neighborhood effect studies. Am J Epidemiol. 2014;180:785-7.

39. Glasziou P, Vandenbroucke JP, Chalmers I. Assessing the quality of research. BMJ. 2004;328(7430):39-41.

40. Stuart EA, Bradshaw CP, Leaf PJ. Assessing the generalizability of randomized trial results to target populations. Prev Sci. 2014. doi: 10.1007/s11121-014-0513-z.
41. Dunning T. Natural experiments in the social sciences: a designbased approach. Cambridge: Cambridge University Press; 2012.

42. Galea S, Riddle M, Kaplan GA. Causal thinking and complex system approaches in epidemiology. Int J Epidemiol. 2010;39(1): 97-106.

43. Auchincloss AH, Diez Roux AV. A new tool for epidemiology: the usefulness of dynamic-agent models in understanding place effects on health. Am J Epidemiol. 2008;168(1):1-8.

44. Wolfson MC. POHEM - a framework for understanding and modelling the health of human populations. World Health Stat Q. 1997;47:157-76.

45. Smith BT, Smith PM, Harper S, Manuel DG, Mustard CA Reducing social inequalities in health: the role of simulation modelling in chronic disease epidemiology to evaluate the impact of population health interventions. J Epidemiol Community Health. 2014;68(4):384-9.

46. Goldie SJ, Daniels N. Model-based analyses to compare health and economic outcomes of cancer control: inclusion of disparities. J Natl Cancer Inst. 2011;103(18):1373-86.

47. Kopec JA, Fines P, Manuel DG, et al. Validation of populationbased disease simulation models: a review of concepts and methods. BMC Public Health. 2010;10:710.

48. Bor J, Moscoe E, Mutevedzi P, Newell ML, Barnighausen T. Regression discontinuity designs in epidemiology: causal inference without randomized trials. Epidemiology. 2014;25(5):729-37.

49. Harper S, Strumpf EC. Commentary: social epidemiology: questionable answers and answerable questions. Epidemiology. 2012;23(6): 795-8.

50. Hernán MA, Taubman SL. Does obesity shorten life? The importance of well-defined interventions to answer causal questions. Int J Obes. 2008;32(S3):S8-S14.

51. Whitehead M, Petticrew M, Graham H, Macintyre SJ, Bambra C, Egan M. Evidence for public health policy on inequalities: 2: assembling the evidence jigsaw. J Epidemiol Community Health. 2004;58(10):817-21.

52.• Glasziou P, Altman DG, Bossuyt P, et al. Reducing waste from incomplete or unusable reports of biomedical research. Lancet. 2014;383(9913):267-76. Makes a compelling argument for how to improve the quality of reporting of biomedical research - and why it matters.

53. Tugwell P, Petticrew M, Kristjansson E, et al. Assessing equity in systematic reviews: realising the recommendations of the Commission on Social Determinants of Health. BMJ. 2010;341:c4739.

54. Susser M, Susser E. Choosing a future for epidemiology: II. From black box to Chinese boxes and eco-epidemiology. Am J Public Health. 1996;86(5):674-7. 